\title{
Een valse oorkonde van Graaf Boudewijn V voor de abdij Ename: de Voogdijregeling van 1064
}

In 1063, stichtte de graaf van Vlaanderen, Boudewijn V en zijn echtgenote Adela van Frankrijk, op de plaats waar het castrum Ename eens het graafschap Vlaanderen had getrotseerd, een benediktijnerabdij aan de Zaligmaker en aan Sint Laurentius toegewijd. De nieuwe abdij werd toevertrouwd aan een communiteit die uit Atrecht was geroepen, en onder de leiding stond van abt Walbrecht ${ }^{1}$.

Voor deze stichting zou graaf Boudewijn V twee oorkonden hebben afgeleverd: de stichtingsoorkonde van 1063 , en een tweede oorkonde gedagtekend 1064, de zogenaamde voogdijregeling ${ }^{3}$.

Daar men voor de zo belangrijke regering van deze «grote markgraaf» over een tijdperk van drie-en-dertig jaren slechts een twaalftal oorkonden bezit en een deel daarvan in de ogen van de diplomatisten niet onverdacht zijn ${ }^{4}$, is het niet zonder belang na te gaan of die beide oorkonden voor Ename echt zijn of niet, vooral omdat zij door de vermaarde professor te Utrecht, O. Oppermann, in zijn eens

1. L. Milis, De abdi, van Ename in de middeleeuwen, in Handelingen der Maatschappij voor Geschiedenis en Oudbeidkunde te Gent, n.r. XV, 1961, blz. 1-48.

Het is geen louter toeval dat graaf Boudewijn einde 1062 te Atrecht verbleef, zie Ph. Grierson, Les annales de Saint.Pierre de Gand et de Saint-Amand (Brussel, 1937), blz. 158.

2. C. Piot, Cartulaire de l'abbaye d'Eename (Brugge, 1881) $\mathrm{n}^{\mathrm{r}} 1$; laatste en betere uitgave: M. Gysseling en A.C.F. Koch, Diplomata Belgica (Brussel, 1950), $\mathrm{n}^{\mathrm{r}}$ 156, blz. 267-268.

3. De voogdijregeling van 1064 geven wij opnieuw uit in Bijlage.

4. Zie, b.v., P. Bernard, Etudes critiques sur les chartes des comtes de Flandre pour Saint-Bertin, in Ecole Nationale des Chartes. Positions des thèses 1923, blz. 7-13, en onze opmerkingen in Revue d'bistoire ecclésiastique, LXI, 1966, blz. 558. 
zo ophefmakende studie over de Aelteren Urkunden des Klosters Blandinium (1928), weliswaar zonder het minste argument, als schwerlich echt werden bestempeld ${ }^{5}$.

In de Inleiding tot zijn jongste en zeer degelijke uitgave van De onuitgegeven oorkonde van de Sint-Salvatorsabdij te Ename vóór 1200 (Brussel, 1965) heeft de historicus van deze abdij, Drs Ludo Milis, het probleem opnieuw aangepakt, en is tot een oplossing gekomen, die wij niet in alles kunnen aanvaarden ${ }^{6}$.

De stichtingsoorkonde van 1063, die nog in origineel voorhanden is, wordt om paleografische argumenten voor echt aangezien. Met deze uitspraak gaan wij zeker akkoord.

Met een scherpzinnige blik voor alle details, die de bevoegde paleograaf verraadt, heeft Ludo Milis aandacht geschonken niet enkel aan het typische oorkondenschrift van de $\mathrm{XI}^{\circ}$ eeuw, maar ook aan het grafelijk monogram, een kenmerk van de oorkonden van sommige graven, van Boudewijn V af tot Boudewijn VII ${ }^{7}$, en vooral aan de rugnota's waarvoor geen enkel middeleeuwse vervalser ooit aandacht heeft gehad.

Dat de voogdijregeling van 1064 eveneens echt zou zijn, kunnen wij moeilijk aanvaarden, en wel om de redenen die wij hier zullen uiteenzetten.

Oorkondetraditie. Laten wij vooraf opmerken dat de originele oorkonde niet meer voorhanden is. De tekst is ons bekend door een afschrift, dat pas uit het laatste kwart van de $\mathrm{XII}^{\mathrm{e}}$ eeuw dateert, en voorkomt op blz. 66 van het Liber privilegiorum van Ename. Weliswaar bezitten wij bovendien een vidimus van het origineel, afgeleverd door abt Egidius van Geraardsbergen op 14 mei 1371. Daar de grafelijke oorkonde van 1064 in een oorkondeninventaris van 1561 niet opgenomen wordt, moet het stuk tussen 1371

5. Deel I (Utrecht, 1928), blz. 333.

6. Inleiding, blz. XXXI-XLI.

7. F. Vercauteren, Actes des comtes de Flandre (Brussel, 1937), Introd., blz. XCVII-XCVIII. 
en 1561 zoek zijn geraakt ${ }^{8}$. Wij zijn dan ook genoodzaakt ons oordeel uitsluitend met interne criteria te staven.

Argumentatie van L. Milis. De argumenten van L. Milis ten voordele van de echtheid dienen eerst onderzocht te worden. Deze geleerde heeft op een uitstekende manier bewezen dat de stichtingsoorkonde, in ieder geval, vóór 1085 is ontstaan, daar zij rugnota's draagt van «de hand A voorkomend op de oorkonden $n^{\text {ns }} 1,2$ en 4 : geschreven tussen 1070 en 1085 " $^{9}$. Maar «het schrift kan enkel bewijzen dat men met een $\mathrm{XI}^{\mathrm{e}}$ eeuwse oorkonde te doen heeft : het gaat om een typische oorkondenschrift van deze tijd...» ${ }^{10}$.

Het bewijs echter van de echtheid van de oorkonde moet elders gezocht worden, namelijk in de getuigenlijst. «De sterfdata der getuigen zijn, voor de abt van St-Vaast Erchenbaldus: 1067 , de abt van St.-Bertijns Bovo: 10 december 1065, de abt van Corbie Fulcho: 1095, Hugo van Oudenaarde: waarschijnlijk kort na 1064, Arnulf van Oudenaarde : tussen 1065 en 1084, Reingot van Gent : tussen 1066 en 1088. Met uitzondering van Fulcho overleefde niemand zeker de eindterm voor een vervalsing van de oorkonde (1085). Maar juist deze getuige had, gezien de verwijdering van de plaats, het minst kontrole. Dat echter Arnulf van Oudenaarde ongeveer zolang leefde als de vervalsing mogelijk was, en tevens de drukke betrekkingen tussen het huis van Pamele en de abdij, maakte een vervalsing voor deze laatste al zeer moeilijk» ${ }^{11}$.

Voor de oorkonde van 1064 blijkt L. Milis a pari geredeneerd te hebben : «Ook voor dit stuk kan men de sterfdata der getuigen als argument der echtheid gebruiken : gravin Adela sterft in $1071^{12}$, haar zoon Boudewijn op 17

8. L. Milis, De onuitgegeven oorkonden, Inleiding, blz. XL.

9. L. Millis, op. cit., blz. XXXII.

10. L. Milis, op. cit., blz. XXXIII.

11. L. Milis, op. cit., blz. XXXIX-XL.

12. Feitelijk is zij op 8 januari 1079, niet in 1071 gestorven, zie 
juli 1070 en Robrecht de Fries op 12 of 13 oktober 1093. Hugo en Arnulf van Oudenaarde, Reingot van Gent en abt Bovo van St.-Bertijns komen ook voor in de eerste oorkonde. Men stelt dus vast dat Robrecht, als graaf oppervoogd der abdij, de uiterste datums voor een mogelijk vervalsing overleeft» ${ }^{13}$.

Daar het echter onbekend is dat op de oorkonde van 1064 , rugnota's van de hand A voorhanden waren, ontbreekt ieder grond voor een dergelijke redenering : de oorkonde kan inderdaad wel in de $\mathrm{XII}^{\mathrm{e}}$ eeuw geschreven zijn. Wat de getuigenlijst van deze tweede oorkonde betreft, is zij blijkbaar uit de stichtingsoorkonde overgenomen : met dode getuigen doet men wat men wil.

De onverdachtheid van de voogdijregeling van 1064 wordt dus niet bewezen. Nu zullen wij de onechtheid ervan aantonen.

Voorbarige «Hospites». Als het er op aankomt zich over de geloofwaardigheid van een oorkonde uit te spreken, die door de impetrant zelf werd opgesteld, in een scriptorium waarvan de diplomatische gebruiken ons slecht gekend zijn, is het eerste wat te doen valt, na te gaan of de taal en de stijl wel deze zijn van het tijdperk door de datum van het stuk aangegeven. Welnu het is hier dat de vervalser opduikt.

Graaf Boudewijn begint met te herinneren aan de omstandigheden waarin hij de kloostervoogdij voor zich zelf en zijn opvolgers voorbehouden heeft, en beschikt heeft de minder belangrijke zaken toe te vertrouwen aan de ondervoogd Arnout van Oudenaarde (injungimus supplere vicem nostri in parvis tantum negociis), en na hem aan die welke de toren van Oudenaarde, de turris Aldenardensis ${ }^{14}$ zullen

N.N. Huyghebaert, Examen des plus anciennes chartes de l'abbaye de Messines, in Bull. Commission royale d'bistoire, CCXXI, 1956, blz. 205 , n. 3.

13. L. Milis, op. cit., blz. XL-XII.

14. J. Dhondt, Het ontstaan van Oudenaarde, in Handel. Geschieden Oudbeidkundige Kring van Oudenaarde, X, 1952, blz. 58, die de 
houden. Aan deze plaatselijke «beschermer» zullen de landbouwers, de hospites en de lijfeigenen van Ename geen andere rechten schuldig zijn dan de cijns van honderd solidi, die de monniken voor hen jaarlijks zullen moeten betalen : de redditibus ruricolarum, bospitum aliorumque mancipiorum ecclesie, pro quibus tuendis laboraturi sunt centum solidos per manus abbatum vel monachorum annuatim eis dari decernimus. Daarmee wordt het an de voogd uitdrukkelijk ontzegd om het even welke rechten aan de onderhorigen van de abdij op te leggen, of ze met boeten af te persen : ea ratione ut nec in ecclesia, nec in omnibus bis que ad ecclesiam pertinent, quicquam juris vel districtionis amplius requirere presumant.

Welnu, alwie met de instellingen van de $\mathrm{XI}^{\mathrm{e}}$ en de $\mathrm{XII}^{\mathrm{e}}$ eeuwen enigszins vertrouwd is, zal niet zonder verwondering in een stuk uit het midden van de $\mathrm{XI}^{\mathrm{e}}$ eeuw de beide woorden bospites en mancipia naast elkaar vermeld zien. Hij zou ze, trouwens, in omgekeerde volgorde willen lezen : eerst de mancipia en dan de bospites. De mancipia, de lijteigenen, behoren tot de $\mathrm{XI}^{\mathrm{e}}$ eeuw ${ }^{15}$; de hospites daarentegen, de laten die zich vrij hebben aangeboden en verlangen vrij te blijven, worden niet voor het einde van de $\mathrm{XI}^{\mathrm{e}}$, zoniet voor het begin van de $\mathrm{XII}^{\mathrm{e}}$ eeuw aangetroffen ${ }^{16}$.

betrouwbaarheid van de oorkonde van 1064 (bij vergissing schrijft hij «van 1063») niet eens betwijfelt, laat opmerken dat men, in de $\mathrm{XI}$ e eeuw, eerder van een castellum zou gesproken hebben; het woord turris, meent hij, «wijst er wellicht op, dat die burcht, in hoofdzaak en opvallend, uit een toren bestond»; wat alles behalve zeker is. In het voorbarige gebruik van het woord turris zouden wij dus een bewijs te meer hebben van de onechtheid van onze oorkonde.

15. In de Actes des comtes de Flandre, 1071-1128, worden de mancipia slechts eenmaal vermeld ( $\mathrm{nr}$ 9, blz. 31) in een oorkonde van Robrecht II voor het St.-Donaaskapittel van Brugge ( 31 oktober 1089 ), die hare dispositiones waarschijnlijk uit een verloren oorkonde van Boudewijn V overgenomen heeft. In de oudste stukken daarentegen door M. Gysseling en A.C.F. Koch, Diplomata belgica, uitgegeven, zal men talrijke mancipia ontmoeten, b.v. nrs 17, 18, 27, $32,49,58,59,68,69,79,80,109,110,170,173,174,195,196$, $229,230, \ldots$

16. In het cartularium van Ename komen de eerste hospites voor 
Om dit vast te stellen, zullen wij drie oorkondenverzamelingen doorlopen.

$1^{\circ}$ Op de 130 nummers van de Actes des Comtes de Flandre, door prof. dr. F. Vercauteren voor een tijdstip van 1070 tot 1128 uitgegeven, treffen wij slechts tweemaal leden van deze sociale stand vóór het jaar 1111 aan ${ }^{17}$. De eerste vermelding komt voor in een oorkonde van Robrecht de Fries, van 1076, die voorzien is van een nagemaakt zegel ${ }^{18}$ : men mag dus wel aan de echtheid van deze oorkonde twijfelen. Voor de echtheid van het tweede stuk, een oorkonde van Robrecht II, van 1100 , voor de monniken van Charroux in Frankrijk, heeft de uitgever zelf niet borg willen staan ${ }^{19}$. Vóór 1111 hebben wij geen onverdacht bewijs van bospites gevonden; vanaf deze datum zijn ze tenonzent geen uitzondering meer ${ }^{20}$.

$2^{\circ}$ In de 236 Noord- en Zuidnederlandse oorkonden door M. Gysseling en A.C.F. Koch onder de titel Diplomata Belgica ante annum millesimum centesimum conscripta samengebracht, is er maar eenmaal sprake van bospites ${ }^{21}$, en wel in de klassieke betekenis van "gasten» of «passante lieden». $3^{\circ}$ Voor het tijdstip 933 tot 1123 hebben wijzelf ongeveer 130 oorkonden van de bisschoppen van Noyon-Doornik voor

in een oorkonde van Diederik van de Elzas van 1140 : Piot $\mathrm{nr} 34$, blz. 35 .

17. Weliswaar ontmoet men in deze oorkonde het woord bospes, bospites, nog in een ander, meer klassieke betekenis : de gasten, de passante lieden, die in een abdij nooit ontbreken, zie F. Vercauteren, Les actes des comtes de Flandre, $\mathrm{nr} 5$, blz. 14.

18. F. Vercauteren, op. cit., nr 4, blz. 9 en 10 ; zie plaat XI.

19. F. Vercauteren, op. cit., nr 24 , blz. 72 . Dezelfde mening deelt prof. dr. A.E. Verhulst, La fondation des dépendances de l'abbaye poitevine de Charroux, dans le diocèse de Thérouanne: Andres, Ham et La Beuvrière; in Le Moyen âge, LIX, 1963, blz. 169.

20. F. Vercauteren, op. cit., nrs $87,99,105,109,111,118,119$, $120,122$.

21. Diplomata belgica, nr 92, blz. 198 : «Insuper omnem decimam de culturis eorum in regno nostro ubi ubi in usus hospitum matriculariorumque habendam penitus absoue uilius refragatione constituimus». De aanwezigheid van de matricularii, d.w.z. de armen die op de lijst van de armendis ingeschreven staan, bepaalt hier de betekenis van hospites : «passante lieden». 
uitgave voorbereid. In deze verzameling treffen wij ook geen hospites vóór 1106 aan ${ }^{22}$. Volledigheidhalve moeten wij een oorkonde vermelden van graaf Herbert van Vermandois voor de abdij Homblières (Frankrijk, Aisne), door bisschop Liudolf tussen 979 en 986 «bekrachtigd», waarin dit woord voorkomt, maar wij hebben hier blijkbaar met een falsum te maken ${ }^{23}$.

Men ontmoet dus geen bospites in Vlaanderen, meer bepaald in Noord-Frankrijk, vóór $1106^{24}$. Het is zeer waarschijnlijk dat zij hier en daar veel vroeger, laat zeggen vóór het einde van de $\mathrm{XI}^{\mathrm{e}}$ eeuw, voorkomen. Of men ze reeds in 1063, d.w.z. in de tijd van de stichting van de abdij van Ename, kan vinden, valt er te betwijfelen ${ }^{25}$. Doch wel-

22. Oorkonde van Baldricus, bisschop van Noyon en Doornik voor de abdij O.L.Vrouw van Broekburg, 1106, uitg. C. Duvivier, Actes et documents anciens intéressant la Belgique, I (Brussel, 1898), blz. 223; zie M. Mollat, Les hôtes de l'abbaye de Bourbourg, in Mélanges Louis Halphen (Parijs, 1951), blz. 513-521.

23. Gallia Cbristiana, $X$ (Parijs, 1751), Instr., kol. 359-360.

24. Wij laten de vraag open, of de submansores ecclesiae, die in 1101 , in de oorkonde van Robrecht II voor het St.-Donaaskapittel, vermeld worden (F. Vercauteren, op. cit., blz. 81, nr 26), niet met de latere bospites te vereenzelvigen zijn. Wat alleszins een bewijs zou leveren dat deze laatste benaming, in het begin van de XII e eeuw, nog niet algemeen gangbaar was. Wat er ook van zij, verschijnen de hospites van St.-Donaas niet vóór 1121, en wel in een oorkonde van Karel de Goede voor de abdij van St.-Winoksberg (F. Vercauteren, op. cit., blz. 238, $\mathrm{nr} 105$; het $\mathrm{nr} 99$ is een latere falsum). Men vindt ze nog in de oorkonden van Boudewijn V (mei 1067) voor dezelfde abdij, maar de passus waar zij voorkomen werd blijkbaar geïnterpoleerd: daar is spraak van scabini, van feodum, enz., allerlei uitdrukkingen die bij de datum niet passen. Wij komen daar wel eens op terug.

25. L'avouerie ecclésiastique belge des origines à la période bourguignonne. Etude d'bistoire ecclésiastique (Gent, 1907), blz. 152, heeft een lange nota over de hospites in Vlaanderen ( IIls se sont spécialement multipliés à l'époque qui nous occupe»: wat nog al vaag is !): de oudste tekst, die hij anhaalt, is een oorkonde voor de abdij van Marchiennes van 1125; verder verwijst hij naar de verouderde studie van C. Duvivier, Hospites. Défrichements en Europe aux XI e, XII ${ }^{\mathrm{e}}$ et XIII $\mathrm{e}$ siècles, in Revue d'archéologie, I, 1859, blz. 75-90; 131-175; P. Roland, Les origines de la commune de Tournai (Brussel, 1931), blz. 152-155, verwijst, voor Doornik, naar teksten van 1108-1193; L. Verriest, Le régime seigneurial dans le comté de Hainaut du XI e siècle à la révolution (Leuven, 1917), blz. $29 \mathrm{vlg}$., heeft enkele zeer belangrijke bladzijden over de nieuwe 
licht zal deze stelling niet onbestreden blijven; er zijn echter nog andere argumenten tegen de echtheid van de betrokken oorkonde; een nieuwe lezing laat immers andere verdachte bijzonderheden aan de dag komen.

Voorbarige strooptochten. Het klooster Ename werd eerst in 1063 gesticht. $\mathrm{Nu}$, amper een jaar later, in 1064, komen de monniken eens te meer bij hun stichters klagen over de strooptochten en plagerijen waaraan zij vanwege hun geburen voortdurend moeten blootstaan : sed quia vicini ejusdem ecclesiae nonnullas molestias ei inferunt, pro quibus ad nos sepe recurrere vos opportet. Indien wij Boudewijn mogen geloven, hebben zij deze stappen meermalen moeten aanwenden (sepe). Wat is nu wel het meest verbazend : de haast waarmee de geburen zich inspannen om de monniken en hun onderhorigen het leven onmogelijk te maken, of de spoed waarmee deze laatsten zich tot hun hoge beschermers wenden?

Feitelijk, om zich ten koste van een klooster te verrijken, wachten de geburen gewoonlijk een gunstig gelegenheid af. Deze biedt zich zelden aan, zo korte tijd na de inplanting van de nieuwe stichting, wanneer de hoge weldoeners nog in leven zijn en hun tengere plant met bezorgdheid gade slaan. Zeer waarschijnlijk hebben de mon-

steden in de $\mathrm{XI}^{\mathrm{e}}$ en XIIe eeuwen; kenmerkend is evenwel dat de oudste tekst met bospites die hij aangeeft, uit 1193 dagtekent. W.M. Newman, Le domaine royal sous les premiers Capétiens (9871180), (Parijs, 1937), blz. 11-14, verklaart eveneens : «On défriche beaucoup au XIe et au XIIe siècle», maar geeft voorbeelden van hospites slechts voor de XIIe eeuw. Wel weten wij dat de oorkonde van graaf Boudewijn V voor Marchiennes (1038), aan dewelke $\mathrm{R}$. Naz een omvangrijke studie heeft gewijd (L'avouerie de l'abbaye de Marchiennes, 1038-1262, Parijs, 1924), een bijzondere aandacht aan de bospites van deze abdij schenkt, en dat J.F. Niermeyer, Mediae latinitatis lexikon minus, afl. 6 (Leiden, 1958), kol. 500, dit stuk, nevens andere even verdachte dokumenten (b.v. de stichtingsoorkonde van St.-Barthélemy van Béthune, z.g. «circa annum 1000», Miraeus-Foppens, Opera diplomatica, II, blz. 945), inroept om de aanwezigheid van bospites in Noord-Frankrijk vóór 1100 aan te tonen. Doch, het zou, o.i., niet moeilijk vallen te bewijzen dat men hier met een vervalsing uit de XII e eeuw te doen heeft. 
niken vrede gekend zolang hun stichters in leven waren. Weliswaar, stierf Boudewijn V op 1 september 1067, maar gravin Adela bleef over hare stichtingen waken : in 1070 trok zij naar Rome en bekwam van Alexander II de pauselijke bescherming voor de jonge abdij ${ }^{26}$. Men zal dus moeilijk kunnen aannemen dat amper een jaar na hare stichting de abdij aan de strooptochten van hare geburen werd overgelaten.

Wanneer wij de overgebleven dokumenten raadplegen, blijkt dit niet vóór het begin van de $\mathrm{XII}^{\mathrm{e}}$ eeuw te zijn gebeurd. De eerste klacht tegen gewelddaden van de geburen, die wij te lezen krijgen, komt eerst in het begin van de $\mathrm{XII}^{\mathrm{e}}$ eeuw voor. Tussen 1116 en 1132 hebben twee grondbezitters van de streek, Flentardus en zijn echtgenote Steinildis, hun allodium aan de abdij geschonken. Kort daarna heeft Wascelinus, broeder van Steinildis, eveneens een allodium geschonken, zeer waarschijnlijk het overgebleven deel van het eens verdeelde goed. Maar, enkele tijd later, nam een zekere Hosto van Marcha (Maarke-Kerkem ?) tegen alle recht het goed in bezit en bracht er verwoestingen op aan, zodat de abt gedwongen werd beroep te doen op de voogd van het klooster ${ }^{27}$. Voogdes was toen Mathildis, vrouw van Pamele-Oudenarde, weduwe van de heer van Pamele-Oudenaarde, Arnout II ${ }^{28}$, en de aanwezigheid van een vrouw in dit ambt legt wellicht de stoutmoedigheid van Hosto en zijn trawanten uit.

26. M. Gysseling en A.C.F. Koch, Diplomata belgica, nr 157, blz. 271 ; vgl. Ibidem, nr 155, blz. 264 (eveneens van 28 januari 1070). De reis van Adela naar Rome wordt vermeld in het Cbronicon Watinense, M.G.H. SS., XIV, blz. 171, en in de Flandria generosa I, M.G.H.S.S., IX, blz. 320.

27. L. Milis, De onuitgegeven oorkonden, $\mathrm{nr} 4, \mathrm{blz}$. 6 . Deze oorkonde werd reeds uitgegeven door F.L. Ganshof, Un cas précoce de distinction entre l'action possessoire et l'action pétitoire en Flandre, in Le moyen âge, LIX, 1963, blz. 259-270, en voorzien van een meesterlijke commentaar, dat wij hier volgen.

28. Deze Mathildis is ongetwijfeld de dochter van Arnout II, heer van Pamele-Oudenaarde, zie C. Piot, Cartulaire de l'abbaye d'Eename, nr 13, blz. 15. 
Het is abt Giselbrecht (1110-1132) die de klachten van de monniken van Ename bij de vrouw van Pamele voorbracht ${ }^{29}$. Het placitum van 1116-1132 stelde hem in het gelijk. Of Hosto en de overige geburen dit vonnis aanvaardden valt te betwijfelen. In 1132 werd abt Giselbrecht naar Sint-Pieters te Gent beroepen ${ }^{30}$ en een zekere Snellardus volgde hem te Ename op. Deze laatste had van zijn onbarmhartige geburen zoveel te verduren, dat hij, rond 1150 , de staf neerlegde en zich met twee confraters in de eenzaamheid terugtrok ${ }^{31}$. De strooptochten van Hosto van Marcha waren dus slechts een begin, wellicht een voorsmaak van de moeilijkheden die de opvolgers van abt Giselbrecht zouden kennen. De donkere jaren van Ename plaatsen zich een kwart eeuw later, rond $1150{ }^{32}$.

Goedkoop bannum. Het bannum dat zoals men weet het recht is te bevelen en te dwingen, is een koninklijk recht, dat uit de openbare potestas voortvloeit. De overtreding van dit bannum werd met een zo belangrijke boete gestraft, dat de schuldige praktisch volledig aan de macht van de heerser overgeleverd was. Deze boete werd dan steeds in goud uitgerekend, d.w.z. dat het een haast onbetaalbare som betekende. De bedreiging met het bannum komt vaak in koninklijke diploma's voor ${ }^{33}$. Vanaf de $\mathrm{XI}^{\mathrm{e}}$ eeuw ont-

29. «Sed predam postea domno abbate Giselberto querimoniam pro hac injuria faciente apud domnam Matthildem...»

30. Ph. Grierson, Les Annales de Saint-Pierre de Gand et de SanntAmand (Brussel, 1937), blz. 40; Annales abbatum monasterii Eenamensis, uitg. U. Berlière, in Documents inédits pour servir d̀ l'bistoire ecclesiastique de la Belgique (Maredsous, 1894), blz. 120.

30. «Snellardus ... qui cum hujus [loci] rexisset ecclesiam aliquot annis, paupertate cogente et emulorum infestacione injuriatus, pastoralem curam deposuit, et parum quid ad sustamentum suum et duorum fratrum quos secum retinuit, ab ecclesia ista accepit», Annales abbatum monasterii Eenamensis, blz. 120-121.

32. Nog rond 1162 bezetten de gebroeders van Maulde en van Spiere onrechtvaardig een allodium door Judith van Zegelsem aan de abdij geschonken: L. Milis, Onuitgegeven oorkonden, $\mathrm{nr} 25$, blz. 18.

33. M. Prou, Recueil des actes de Pbilippe Ier, roi de France (Parijs, 1908), Introd., blz. CX-CXIII, en G. Tessier, Diplomatique royale française (Parijs, 196), blz. 227 en 252. 
moet men het ook in de oorkonden van menige landsheren, namelijk van de graven van Vlaanderen ${ }^{34}$.

Terecht heeft L. Milis deze sanctio bij enkele oorkonden van Boudewijn $\mathrm{V}$ aangetekend ${ }^{35}$. Wat hij echter niet bemerkt heeft, is dat deze boete steeds in goud is berekend ${ }^{36}$. In de oorkonde van 1064 daarentegen wordt een boete in zilveren munt opgelegd, en dan nog een betrekkelijk geringe som: michi vel heredi meo XL marcas argenti persolvat; een som dus, die niet meer de mateloosheid uitdrukt van de koninklijke potestas, maar die door de overtreder werkelijk dient betaald te worden. Het is inderdaad een goedkoop bannum, dat de onechtheid van de oorkonde eens te meer duidelijk in het daglicht stelt.

Baatzucbtige voogden. Er bestaat geen twijfel meer : de voogdijregeling van 1064 is een falsum. Het stuk werd inderdaad later opgemaakt, toen vrije laten (bospites) zich rond de abdij waren komen vestigen, tevens dicht, te dicht,

34. Bijvoorbeeld bij de hertogen van Normandië, zie M. Fauroux, Recueil des actes des ducs de Normandie (Caen, 1961), nrs 2, 13, 53, 69, 70, enz.; de graven van Tonnerre: M. Quantin, Cartulaire général de l'Yvonne, I (Auxerre, 1854) nr. 90, 92, enz. Al deze voorbeelden dateren uit de $\mathrm{XI}$ e eeuw.

35. De oorkonde van graaf Boudewijn V voor St.-Bertijns, 6 januari 1042 ( «Le premier diplôme, seul authentique, de Baudoin V pour l'abbaye de Saint-Bertin», volgens P. Bernard, op. cit., blz. 5) : «V libras auri principi persolvere cogatur», D. Haigneré, Les chartes de Saint-Bertin, I (St.-Omer, 1886), nr 71, blz. 25; de stichtingsoorkonde van Ename (1063): «Si quisquam contra Deum et bannum nostrum facere presumpsit, pro banno ... XXII marcas auri persolvet», C. Piot, Cartulaire de l'abbaye d'Eename, nr 1, blz. 3 ; de stichtingsoorkonde van het St.-Pieterskapittel te Rijsel (1066) : «Si quis autem his in aliquo contraïre aut contradicere voluerit, centum libras auri persolvat et bannum regis», E. Hautcoeur, Cartulaire de l'église collégiale de Saint-Pierre de Lille, I (Rijsel-Parijs, 1894), blz. 7 ; Robrecht II voor het St.-Donaaskapittel te Brugge, 31 oktober 1089 (waarschijnlijk overgenomen uit een oudere, verloren oorkonde van Boudewijn V) : «Si quis autem his in aliquo contraire vel contradicere voluerit C. libras auri persolvat», F. Vercauteren, Actes des comtes de Flandre, nr 9, blz. 32.

36. In Normandië werd het bannum meermaals in zilveren gerekend, maar dan bedraagt het een ongehoord grote som geld : Juizend pond, M. Fauroux, Recueil des actes des ducs de Normandie, nr 225, blz. 434 . 
bij de turris Aldenardensis, het slot van de machtige heren van Pamele, voogden van de St.-Salvatorsabdij.

Dat de voogden van Ename het zeer druk hebben gehad in de loop van de $\mathrm{XII}^{\mathrm{e}}$ eeuw, hebben wij aangetoond. Dat zij voordeel uit deze toestand hebben gehaald, lijdt evenmin twijfel. Een regeling bleek dan ook noodzakelijk; voortaan zouden de voogden er van afzien de laten (mancipia en bospites) van de abdij met allerlei onrechtvaardige boeten en karweien te overladen; zij zouden zich met een jaarlijks cijns van honderd solidi tevreden stellen.

Deze regeling werd zeer waarschijnlijk slecht nageleefd, en de arme ruricolae werden weldra op allerlei manieren opnieuw uitgebuit. Dit strookte met de gebruiken van deze ellendige tijden, en de bisschoppen, in 1148 te Reims vergaderd, hebben wellicht aan de heren van Pamele gedacht toen zij hun krachtig protest ophieven : «Auctoritate apostolica prohibemus, ut nullus advocatus praeter jus et beneficium antiquitus constitutum aliquid sibi accipere vel usurpare presumat. Subadvocatos vero vel exactores eorum modis omnibus ab ecclesiarum infestationibus removeri praecipimus» ${ }^{37}$. Een bewijs hiervoor zullen wij, in het cartularium van Ename, niet lang moeten zoeken. Het stuk dat de misbruiken van onze voogden aanklaagt, komt tevens de oorsprong van de zogezegde voogdijregeling belichten.

In 1154, doet Arnout van Oudenaarde, zoon van Geraard, eertijds kamerheer van Vlaanderen ${ }^{38}$, afstand, vrijelijk en voor immer, van alle rechten die hij had uitgeoefend, op de laten die «van alle kanten, rond de abdij waren komen wonen». Zijn rechten op deze vreemdelingen (advenae) beweerde hij van zijn ouders te hebben geërfd. Hij ontzegd zich voortaan ( $a b$ bac die et deinceps) om het even welke nieuwe lasten aan deze laten op te leggen, hetzij geldelijke lasten (exactiones), hetzij karweien (coactum servitium).

37. Mansi, Concilia, XXI, kol. 715, aangehaald bij C. Pergameni, L'avouerie ecclésiastique belge, blz. 152, n. 3.

38. L. Milis, Les seigneurs de Pamele-Audenarde, blz. 49-53. 
Die afstand doet hij zowel in zijn eigen naam als uit naam van zijn ambtenaren: een zekere Geraard Colckwage en diens zoon Godescalc. Zijn broeders Boudewijn, Gillis en Olivier ondertekenen deze oorkonde, eveneens zijn manschappen, twee en twintig in getal ${ }^{39}$.

Het stuk is kort. Men moet het aandachtig lezen. Hier wordt duidelijk te verstaan gegeven : $1^{\circ}$, dat Arnout vroeger (antea) zijn voogdijschap niet enkel over de ruricolae en de lijfeigenen (mancipia) dacht te mogen uitoefenen, maar ook over de vrije laten (advenae) die zich van alle kanten op de gronden van de abdij waren komen vestigen; dat hij aan hen ook allerlei lasten en karweien wilde opleggen, en dit zonder enig recht of aanneembare reden; $2^{\circ}$, dat hij nu aan al deze misbruiken verzaakte, maar niet aan de rechten die hem vroeger toebehoord hadden (antea pertinuerint).

Het waren dus vooral de advenae, de illic undicumque venientes die het van de voogd te verduren hadden. Aan hen, aan de hospites, heeft de valse oorkonde van 1064 ook speciaal gedacht, en men verstaat ook waarom het stuk Arnout «en gelijk welke van zijn nakomelingen» (vel quisquam successores ejus) met een boete van veertig zilveren marken uitdrukkelijk heeft willen bedreigen.

Men mag dus aannemen dat de valse oorkonde van 1064 kort vóór 1154 werd gemaakt. Het is dus met dit stuk dat de monniken van Ename hun machtige voogd tot een minnelijk akkoord hebben trachten te brengen.

Volstond het een valse oorkonde te maken om tot een dergelijke regeling te komen ? Dit valt zeer te betwijfelen : men mag niet te gemakkelijk aan de gunstige uitslagen van zoveel valse oorkonden geloven. Zeer dikwijls waren zij niets anders dan een uitnodiging om rond de tafel te gaan zitten en het geschil zakelijk te bespreken.

In 1154 is dat zeer waarschijnlijk ook het geval geweest. Wat de oorkonde van Pamele over deze onderhandelingen

39. C. Piot, Cartulaire de l'abbaye d'Eename, nr. 42, blz. 42-43. 
niet zegt, kunnen wij uit een andere oorkonde van dezelfde heer, van het volgend jaar, naar voren brengen.

In 1155 was opnieuw een betwisting tussen de burggraaf en de monniken van Ename. Het ging ditmaal om een watermolen te Merc (Kortemark ?) ${ }^{40}$, of liever, om twee watermolens, want, op dezelfde rivier, stroomafwaarts, had nu Arnout zijn eigen watermolen gezet, met het gevolg dat de abdijmolen vlug onder water stond. Dank zij de tussenkomst van wederzijdse vrienden, mediantibus utrorumque amicis, kon de zaak beslecht worden : de monniken zouden de heerlijke molen, op eigen kosten, elders mogen herbouwen; de verlaten grond zouden zij daarbij van Arnout in pacht nemen ${ }^{41}$.

Het geschil rond de twee watermolens kon dus, dank zij de tussenkomst van goede vrienden, tot een minnelijke regeling gebracht worden. Nochtans, is het, voor Arnout, een goede zaak geweest : de afstand door de voogd werd door de monniken duur betaald.

De voogdijregeling van 1154 moet van dezelfde aard geweest zijn. Hier hebben de monniken eveneens de afstand van Arnout van enkele van zijn geusurpeerde voogdijrechten duur moeten betalen. Wat hebben zij daarvoor moeten geven ? De bewaarde teksten zeggen het ons niet. Het moet nochtans een niet te versmaden prijs geweest zijn, want de koper mocht een premie ontvangen. Aan Arnout's oorkonde werd, op het einde van de onderhandelingen ${ }^{42}$, nog een laatste dispositio na de getuigenlijst bijgevoegd: Praeterea quicquid juris in Ehamensi teloneo de festis sancti Laurentii babere solebam, in perpetuum coram eisdem testibus ecclesie Ebamensi dono.

Deze laatste clausule noemde ik zo pas een «premie aan

40. Eerder Kortemark (Merc in de oorkonden), West-Vl., canton Torhout, dan Maarke-Kerkem (steeds Marca ofwel Marcha in de teksten), Oost-V1., canton Oudenaarde.

41. C. Piot, Cartulaire de l'abbaye d'Eename, nr 43, blz. 43-44.

42. "Op het einde der onderhandelingen», omdat de oorkonde blijkbaar reeds geschreven was. 
de koper». Dat is misschien wat overdreven : zo mild zal Arnout niet geweest zijn! Integendeel. Wij hebben nog een zinnetje uit zijn oorkonde onopgemerkt gelaten : zijn vrije afstand van al de door hem zo lang gepleegde misbruiken, deed Arnout voor zijn zielelafenis en voor deze van zijn ouders : pro salute anime mee et parentum meorum. Dat wil waarschijnlijk zeggen dat Arnout's ouders niet veel eerlijker waren geweest dan hij zelf; dat wil ook zeggen dat de monniken, omwille van deze afstand, jaarlijks voor de zielerust van hun vervolgers zouden moeten bidden. Dat hebben de kloosterlingen nog al kras gevonden. Arnoud moet daaraan gehouden hebben : wellicht was zijn berouw toch echt ! De tolvrijheid op de St.-Laurensdagen ${ }^{43} \mathrm{kwam}$ de zaak vereffenen : een zuivere gift is het zeker niet, doch een eerlijk bedongen prijs.

De steeds toenemende bloei van de stad Oudenaarde in de loop van de $\mathrm{XII}^{\mathrm{e}}$ eeuw moet trouwens, aan de geduchte voogd, een voldoende vergoeding hebben bezorgd.

Vervalser. Kunnen wij nu iets over de vervalser zelf vernemen, hem enigszins identificeren? Dit zal wel niet volstrekt onmogelijk zijn.

In zijn regesten van graaf Diederik van de Elzas, laat H. Coppieters Stochove opmerken, dat deze graaf nog niet over een georganizeerde kanselarij beschikte, en dat zijn oorkonden bijna regelmatig door de impetrant zelf werden opgesteld. Als voorbeeld, geeft hij twee oorkonden voor Ename aan; beide, merkt deze geleerde op, bedragen een geldelijke sanctie, en hij verwijst naar Piot $\mathrm{n}^{\mathrm{r}} 36$ (een oorkonde van 1144) en naar Piot $\mathrm{n}^{\mathrm{r}} 44$ (een andere oorkonde van 1146) ${ }^{44}$.

Indien wij nu de voogdijregeling van 1064 naast de oor-

43. S. Laurentius is, naast de Verlosser en O.L.Vrouw, de patroon van de abdij; hij wordt gevierd op 10 augustus.

44. Régestes de Thierri d'Alsace, comte de Flandre, in Handelingen der Maatschappij van Geschied- en Oudbeidkunde te Gent, IV, 1902, blz. 207. 
konde van 1144 plaatsen, zullen wij onmiddellijk een onbetwistbare stijlgelijkenis vaststellen :

XXXmarcas argenti michi vel ... Pro contemptu nostro et temeberedi pro contemptu ritate sua, michi vel beredi meo persolvat. XL marcas argenti persolvat.

De zinswending michi vel beredi meo XL marcas argenti persolvat komt in $\mathrm{n}^{\mathrm{r}} 44$ eveneens terug.

De stijlontleding van deze twee oorkonden, Piot $n^{\text {rs }} 36$ en 44 , - die wij om haar al te saai karakter de lezer willen sparen - zou ons dezelfde dictator in de $n^{r s} 33,37,40,42$, 43 en 47 helpen terugvinden ${ }^{45}$. Om het in één woord te zeggen, de vervalser is een monnik van Ename aan wie nog acht andere oorkonden mogen toegeschreven worden; hij is tussen 1140 en 1158 werkzaam geweest, d.w.z. onder de voogdij van Arnout III van Oudenaarde (1145/50 - c. 1162).

Hij blijkt nergens zijn naam prijsgegeven te hebben. Wij zijn echter over de samenstelling van de communiteit van Ename, in die tijd, zeer goed ingelicht. Een oorkonde van 1150, door abt Snellardus van Ename aan de cisterziensers van Cambron afgeleverd, draagt de suscripties van veertien monniken, d.w.z. van de voltallige communiteit van St.Salvator ${ }^{46}$. De vervalser moet zich onder deze veertien namen bevinden. Méér kunnen wij niet zeggen.

Besluit. Wij kunnen nu besluiten: de zogenoemde voogdijregeling van 1164 voor Ename is een falsum, dat tussen 1140 en 1158, waarschijnlijk nog vóór 1154 door een monnik van Ename werd opgesteld, om de laten en de bospites van zijn abdij tegen de afpersingen van hun voogd, Arnout III van Pamele-Oudenaarde, te verdedigen. Zijn pogingen hebben een gunstig gevolg gehad. Waarschijnlijk door tussenkomst van wederzijdse vrienden, verzaakte Arnout, in

45. Een kenmerk van onze schrijver is het herhaaldelijke gebruik van het woord deinceps. Doch wij moeten toegeven dat het in Piot nr 3 niet voorkomt.

46. C. Piot, Cartulaire de l'abbaye d'Eename, nr 40, blz. 41. 
1154, aan enkele van de door hem gepleegde misbruiken. Deze afstand gebeurde niet kosteloos, doch de monniken betaalden ze duur genoeg om zich daarnaast, op de St.Laurensdagen, nog de tolvrijheid te zien vergunnen.

N.N. HUYGHEBAERT, O.S.B.

Boudewijn, prins der Vlamingen, om gevolg te geven aan de klachten van de monniken van Ename, die door bun geburen lastig werden gevallen, vertrouwt de ondervoogdij van de abdij aan Arnout van Oudenaarde toe, en aan ben die, na bem, in 't bezit zullen zijn van de burcht (turris) van Oudenaarde; bijzelf behoudt zich de oppervoogdij voor.

Sint-Omaars, 1064.

A. SCHIJNBAAR-ORIGINEEL niet voorhanden. Het zou gezegeld zijn op staart.

B. VIDIMUS door Egidius 1, abt van Geraardsbergen, gedateerd van 1 mei 1371. Rijksarchief te Ronse (vroeger te Gent, fonds Ename, Oorkondenschat nr 3. Naar $A$. - C. Afschrift 1615 van de vidimus door notaris J. Vanden Broucke. Rijksarchief te Ronse, fonds Ename, bundel $40 \mathrm{nr} 2$.

D. AFSCHRIFT uit de laatste kwart van de XIIe eeuw in de Liber privilegiorum onder de rubriek: «Balduinus comes de libertate ecclesie» ( $\mathrm{Er}$ volgen nog twee lijnen, die geschrapt werden). Naar $A$. - E. Afschrift uit het einde van de XIII e euw in het eerste cartularium van Vlaanderen (rubriek weggeschrapt). Archives départementales du Nord te Rijsel, B 1561, fo 56. - F. Afschrift uit het einde van de $\mathrm{XVe}$ eeuw. Rijksarchief te Ronse, fonds Ename, nr 4, $\mathrm{f}^{\circ}$ 4 v- 5 v. Naar D. - G. Afschrift uit de XVe eeuw, onder de rubriek : "Copia advocacie dicte ecclesie Eybamensis per Balduino comite domino Aldenardensi in parvis negociis comisse». Rijksarchief te Ronse, fonds Ename, nr 5 , fo 2 v. - H. Afschrift uit de XVe of het begin van de XVIe eeuw, onder de rubriek: "Balduinus comes de libertate ecclesiae». Rijksarchief te Ronse, fonds Ename, nr 7, fo XII r-v. Naar D. I. Afschrift uit de XVII e euw in de Cbronijcke ende privilegen van Audenaerde, fo XII v-XIII r. Stadsarchief van Oudenaarde, Oud archief. «Ex vetusto manuscripti codice Davidys Pamelii».

UITGAVEN : a) Miraeus, Diplomata Belgica (Brussel, 1627), blz. 66-67; naar $D$ ? - b) A. Miraeus, Notitia ecclesiarum Belgii (Antwerpen, 1630), blz 178; naar D? - c) Miraeus-Foppens, Opera diplomatica, I (Leuven, 1723), blz. 153 ; naar $a$ of b. - d) C. Van

1. En niet Geraard, zoals L. Milis, Onuitgegeven oorkonden, Inleiding, blz. XL, bij vergissing schrijft. 
Gestel, Historia sacra et profana archiepiscopatus Mecbliniensis, II (Den Haag, 1725), blz. 248; naar c. - e) L. A. Warnkoenig, Flandrische Staats- und Rechtsgescbicbte, III, 2de deel (Tübingen, 1839), blz. 225, nr cxxxx; naar E. - f) C. Piot, Cartulaire de l'abbaye d'Eename (Brugge, 1881' blz. 5-6, nr 3; naar D. - g) E. Beaucarne, Notice sur la commune d'Eename, $2 \mathrm{e}$ partie: Histoire de l'abbaye d'Eename (Gent, 1895), blz. 4-5 (Franse vertaling).

VERMELDINGEN : A. Le Glay, Revue des Opera diplomatica de Miraeus (Brussel, 1856), blz. 24. - A. Wauters, Table chronologique, I (Brussel, 1866) blz. 514. - A. Wauters, Table cbronologique. Supplément, VII, 1e deel (Brussel, 1885), blz. 144. - C. Pergameni, L'avouerie ecclésiastique belge des origines à la période bourguignonne (Gent, 1907), blz. 210. - S. Bormans en J. Halkin, Table chronologique, XI, 1e deel (Brussel, 1907), blz. 67. - L. Milis, Onuitgegeven oorkonden van de Sint-Salvatorsabdij te Ename vóór 1200 (Brussel, 1965), Inleiding, blz. XXXI-XLI.

Onze uitgave volgt de tekst $D$. De cursief gedrukte tekst werd overgenomen uit Piot nr 1 (oorkonde van graaf Boudewijn V, 1063 ) en nr 36 (oorkonde van graaf Diederik van de Elzas). Het afschrift $I$, van de hand van een kopiïst blijbaar onbekend met het Latijn, is te gebrekkig om bij het herstellen van de tekst te kunnen dienen. Het blijkt trouwens van $D$ af te hangen.

Balduinus, per Dei clementiam princeps Flandrensium, Walberto abbati de Eiham (a) ejusque successoribus salutem. Quoniam ecclesia Eihamensis (b), cui preestis, a me et a conjuge mea Adela, precipue fundata de mensa nostra, beneficia quibus monachi vivere (c) debeant, accepit, dignum duxi advocatiam ejusdem ecclesia in manu mea et successorum meorum comitum retinere. Sed quia vicini ejusdem ecclesie nonnullas (d) molestias ei (e) inferunt, pro quibus ad nos sepe recurrere (f) vos opportet, nos vero circa $(\mathrm{g})$ curam nostri principatus occupati, de singulis minutis rebus non valemus ad adjutorium vestrum venire, alia via aggressi (h) sumus vobis consultum ferre. Igitur Arnulfo de Aldenardo, quia vobis vicinus est, injungimus supplere vices nostri, in parvis tantum (i) negotiis, nobis majora reservantes. Quod ut oportune et fideliter agat, vel ipse vel quicumque successorum ejus (j) turrim Aldenardensem tenuerit, de redditibus ruricolarum, hospitum, aliorumque mancipiorum ecclesie, pro quibus tuendis laboraturi

(a)Eyham B, I, Eham E, F. - (b) Eyhamensis B, I, Ehamensis $E, F$. - c) vivere : in de linkse rand door dezelfde band $D$. - (d) nonnullas eis $E$. - (e) ei : ontbreekt E. - (f) recurre $D, F$; recurre : verbeterd in recurrere $H$. - (g) nos contra curam $E$. - (h) aggressa $E$. - (i) in parvis enim $E$. - ( $\mathrm{j})$ ejus : tussen de lijnen in $D$; ontbreekt $E$. - (k) quod $E$. - (1) 
sunt, centum solidos, per manus abbatum vel monachorum annuatim ei dari decernimus, ea ratione ut $(\mathrm{k})$ nec in ecclesia nec in omnibus his (1) que ad ecclesiam pertinent, quicquam juris vel districtionis amplius $(\mathrm{m})$ requirere presumant. Tanta enim libertate ipsam ecclesiam donavimus, ut omnium et hominum et aliarum rerum, ad eam pertinentium, in tota nostra dicione, nullum alium advocatum preter me, vel $(\mathrm{n})$ heredem meum comitem Flandriarum ( $\mathrm{o}$ ) esse decreverim ( $p$ ). Si ergo prefatus Arnulfus, vel quisquam successorum ejus, hanc constitutionem nostri privilegii transgressus, bannum nostrum infregerit, pro contemptu nostro et temeritate sua, michi vel heredi meo XI marcas argenti (q) persolvet et ecclesie quod suum est restituet.

Actum est boc ( $\mathrm{r}$ ) apud Sanctum Audomarum, presente conjuge mea ( $\mathrm{s}$ ) Adela, filiis meis Balduino et Roberto; Bovone abbati Sancti Bertini, Hugone, Arnulfo $(t)$ de Aldenardo (u), Reingot (v) de Ganda, M $^{\circ} \mathrm{LXIIII}^{\circ}$ (w), indictione secunda $(x)$.

hiis $B, I$, ontbreekt $E$. - (m) amplius: ontbreekt $E-$ (n) et $E$. - (o) Flandrensium $E-(p)$ decernimus $E$. (q) argenti : ontbreekt $E$. $-(\mathrm{r})$ hoc : ontbreekt $E$. - (s) mea: ontbreekt E. - ( (t) Arnulpho E, I. - (u) Aldenarde E. (v) Reingneto $E$. - (w) $\mathrm{M}^{\circ} \mathrm{LX}^{\circ} \mathrm{IIII}^{\circ} E .-(\mathrm{x})$ indictione secunda: ontbreekt $E$. 